\title{
Phenolics in Primula veris L. and P. elatior (L.) Hill Raw Materials
}

\author{
Katarzyna Bączek, Jarosław L. Przybył, Małgorzata Mirgos, Olga Kosakowska, \\ Izabela Szymborska-Sandhu, and Zenon Węglarz
}

\begin{abstract}
Laboratory of New Herbal Products, Department of Vegetable and Medicinal Plants, Warsaw University of Life Sciences-SGGW, Nowoursynowska 166, 02-787 Warsaw, Poland
\end{abstract}

Correspondence should be addressed to Katarzyna Bączek; katarzyna_baczek@sggw.pl

Received 3 March 2017; Revised 7 June 2017; Accepted 27 June 2017; Published 1 August 2017

Academic Editor: Ravi Ramasamy

Copyright (C) 2017 Katarzyna Bączek et al. This is an open access article distributed under the Creative Commons Attribution License, which permits unrestricted use, distribution, and reproduction in any medium, provided the original work is properly cited.

\begin{abstract}
Primula veris L. and Primula elatior (L.) Hill represent medicinal plants used for the production of herbal teas and preparations with antioxidant and expectorant activity. Flowers and roots of both species possess the same biological activity. In the presented study, raw materials of wild growing $P$. veris and P. elatior were compared in terms of the content and composition of phenolic compounds using a fast and simple HPLC-DAD method. The study showed that flowers of both species were rich in flavonoids. However, $P$. veris flowers were characterized with a distinctly higher content of isorhamnetin-3-O-glucoside, astragalin, and (+)-catechin, whereas $P$. elatior occurred to be a richer source of rutoside and isorhamnetin-3-O-rutinoside. Hyperoside was found exclusively in P. elatior flowers. Phenolic glycosides (primverin and primulaverin) were identified only in the roots. Their content was about ten times higher in $P$. veris in comparison with P. elatior underground organs. The obtained results clearly show that both Primula species differ distinctly in terms of the content and composition of phenolic compounds. The compounds differentiating both species to the highest degree (hyperoside, in flowers, as well as primverin and primulaverin, in the roots) may be useful chemical markers in the identification and evaluation of both species.
\end{abstract}

\section{Introduction}

Cowslip (Primula veris L., syn. P. officinalis Hill) and oxlip (Primula elatior (L.) Hill) are small, long-lived perennials from the family Primulaceae, growing wild in temperate Europe and Asia [1]. Cowslip grows on nutrient-poor grasslands, herb-rich meadows, and at the edges and in clearings of warm and bright woodlands. Oxlip prefers moist and shaded forests, but it also grows in mountain meadows $[2,3]$. Both species produce a rosette of leaves and leafless flower stalks, up to $20-30 \mathrm{~cm}$ high. Cowslip flowers are fragrant, brightyellow with orange spots at the edge of each lobe. They are formed at the top of the stalks in an umbel-like inflorescence. In turn, the pale-yellow, almost scentless, flowers of oxlip are produced on separate stalks. In the central part of these flowers an orange ring is visible $[1,2]$. Underground organs consist of slightly curved, grayish-brown rhizomes with yellowish-white (P. veris) or brown (P. elatior) roots, commonly called roots $[1,4]$.

Both species have a long history of medicinal use. In the current (fifth) edition of the European Pharmacopeia, they are listed as a source of Primula roots [4]. However, in the British Herbal Pharmacopeia [5] as well as in Pharmacopee Française [6], only P. veris is mentioned as a source of Primula raw materials.

Primula veris and P. elatior have mainly been exploited for the production of herbal teas and preparations that are also considered dietary supplements [1]. They indicate various pharmacological activities, for example, secretolytic, expectorant, anti-inflammatory, diuretic, antimicrobial, antifungal, and sedative [7-10]. According to EMA, Primula flowers and roots are used against coughs, bronchitis, and catarrhs of the respiratory tract and also to treat nervousness, headache, or rheumatism $[7,8]$. In the past, Primula leaves and flowers 
were also eaten raw or cooked as a source of vitamins and microelements available in late winter [11]. Apart from $P$. veris and $P$. elatior, other Primula species are described as also revealing some medicinal potential. According to Demir et al. [12], P. vulgaris demonstrates antioxidant activity. Extracts from $P$. denticulata show cytostatic properties, while P. macrophylla shows antifungal ones [13-15].

The main active compounds of Primula flowers and roots are triterpene saponins as well as phenolic compounds, including flavonoids (about 3\% in flowers), phenolic acids, and phenolic glycosides $[7,8]$. Saponins are responsible for secretolytic and expectorant activity. In turn, phenolic compounds, present especially in Primula flowers, reveal antioxidant, antimicrobial, and cytostatic properties [12, 13].

Phenolic compounds can be easily separated on a C18 reversed-phase (RP) column and detected using a UV or diode array detector (DAD) [16-19]. All these substances contain at least one aromatic ring and thus efficiently absorb UV light. So, the UV spectra obtained by the DAD are a valuable indicator in screening and preliminary qualitative analyses of the different groups of phenolics. For better structure elucidation of metabolites and/or unambiguous identification of target compounds, liquid chromatography mass spectrometry (LC-MS) techniques or even nuclear magnetic resonance (NMR) detection are used [17-19].

Based on European Medicines Agency (EMA) and European Pharmacopeia monographs, Primula preparations are produced exclusively out of $P$. veris and $P$. elatior raw materials, which are considered to possess the same values $[4,7,8]$. Due to the developmental and morphological similarities between both species, they are hard to differentiate on natural sites, and after the drying process the raw materials collected from them are indistinguishable. Despite the above regulations, some authors report differences between these two species in terms of their chemical composition $[1,7,8]$. Other herbal raw materials, even those described in pharmacopeias, are very often provided by two or even three plant species. For example, the lime flower is collected from Tilia platyphyllos Scop., Tilia cordata Mill, and their hybrid Tilia $\times$ vulgaris [4]. Numerous studies confirm that the quality of such materials may be highly diversified, which is undesirable from an industrial point of view [20-22].

The aim of our study was to compare wild growing $P$. veris and $P$. elatior in terms of the accumulation of phenolic compounds as chemical markers for species identification and more accurate assessment of raw materials, in the context of their potential usage, by a simple, but reliable, analytical method on a standard HPLC-DAD system.

\section{Materials and Methods}

2.1. Plant Material. Flowers and roots of $P$. veris and $P$. elatior were collected in the eastern part of Poland from eight wild growing populations of each species. The plant material from one population was used as one replication for chemical evaluation. Flowers were collected at the stage of full flowering (in May, Figures 1 and 2) from randomly chosen plants (about $150 \mathrm{~g}$ of fresh flowers per population). Roots

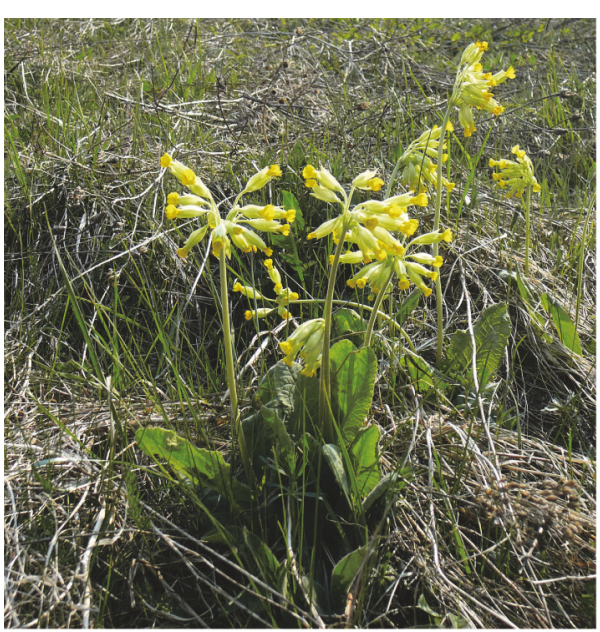

FIGURE 1: Cowslip (Primula veris).

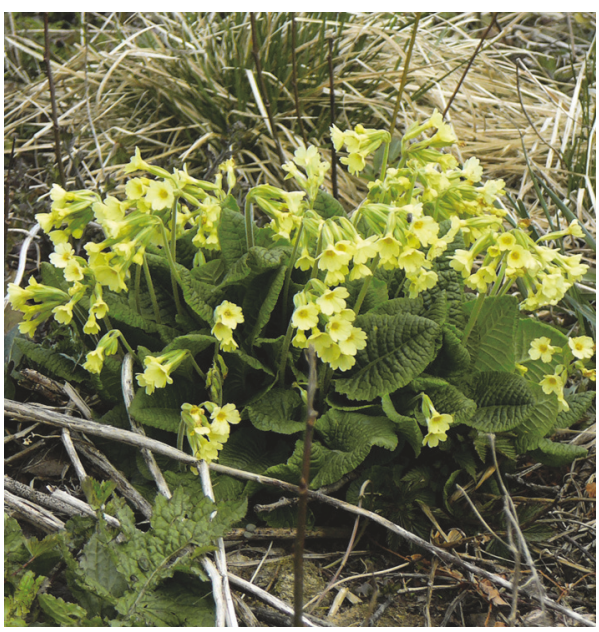

Figure 2: Oxlip (Primula elatior).

were harvested from the same populations in September, after seed setting (about $500 \mathrm{~g}$ of fresh roots per population). They were washed and cut into pieces. Both sets of raw materials were dried at $40^{\circ} \mathrm{C}$. Voucher specimens were taken from each population. These are stored in the Department of Vegetable and Medicinal Plants, WULS-SGGW.

2.2. HPLC Analysis. Air-dry, finely powdered, and homogenized raw material $(1.000 \mathrm{~g})$ was extracted with $100 \mathrm{ml}$ of methanol (Sigma-Aldrich, Poznań, Poland, reagent grade) in a Büchi Labortechnik AG B-811 Extraction System. Soxhlet hot extraction was used with twenty-five extraction cycles, flushing and drying. After evaporation of solvents, the residue was dissolved in $10 \mathrm{ml}$ of methanol. The obtained extracts were filtered with a Supelco Iso-Disk ${ }^{\mathrm{TM}}$ Syringe Tip Filter Unit, a PTFE membrane, diameter $25 \mathrm{~mm}$, pore size $0.20 \mu \mathrm{m}$ and injected in triplicate. Separation was achieved using a modern C18 reversed-phase, Kinetex ${ }^{\mathrm{TM}} 2.6 \mu \mathrm{m}, 100 \mathrm{~mm}$ $\times 4.60 \mathrm{~mm}$ column with a porous outer layer on solid silica core particles (Phenomenex ${ }^{\circledR}$, USA). The analyses were 
TABLE 1: Validation parameters of the HPLC-DAD analysis $(n=6)$.

\begin{tabular}{|c|c|c|c|c|c|c|c|}
\hline Compound & $\begin{array}{l}\text { Purity } \\
(\%)\end{array}$ & $\begin{array}{c}\text { Precision } \\
\text { intraday } \\
(\mathrm{CV}, \%)\end{array}$ & Calibration equation & $\begin{array}{l}\text { Linearity } \\
\qquad\left(r^{2}\right)\end{array}$ & $\begin{array}{l}\text { Linear range } \\
(\mathrm{mg} / \mathrm{mL})\end{array}$ & $\begin{array}{l}\text { LOD } \\
(\mu \mathrm{g} / \mathrm{L})\end{array}$ & $\begin{array}{c}\text { LOQ } \\
(\mu \mathrm{g} / \mathrm{L})\end{array}$ \\
\hline /+/-Catechin & 98,3 & 0.80 & $y=8216.4 x-6069.3$ & 0.9995 & $0.492-49.150$ & 11.07 & 36.10 \\
\hline Luteolin 8-C-glucoside (orientin) & 99,4 & 1.12 & $y=2407.3 x-2358.1$ & 0.9998 & $0.497-49.700$ & 36.84 & 122.83 \\
\hline Quercetin 3-O-rutinoside (rutoside) & 91,4 & 1.61 & $y=1434.0 x-5093.0$ & 0.9999 & $0.907-90.669$ & 74.60 & 248.80 \\
\hline Quercetin 3-O-galactoside (hyperoside) & 95,0 & 1.48 & $y=3435.5 x-6882.2$ & 0.9999 & $0.384-38.400$ & 35.16 & 117.20 \\
\hline Isorhamnetin-3-O-rutinoside & 95,1 & 1.09 & $y=2096.1 x-904.8$ & 0.9998 & $0.380-38.000$ & 29.31 & 97.69 \\
\hline Isorhamnetin-3-O-glucoside & 95,3 & 1.02 & $y=1940.0 x-897.4$ & 0.9998 & $0.380-38.000$ & 33.90 & 113.00 \\
\hline Kaempferol 3-O-glucoside (astragalin) & 99,4 & 1.68 & $y=2104.5 x-2426.3$ & 0.9999 & $0.410-81.906$ & 33.00 & 109.90 \\
\hline 3-O-Caffeoylquinic acid (chlorogenic acid) & 98,64 & 1.24 & $y=6517.4 x-12016.6$ & 0.9997 & $0.395-39.456$ & 20.97 & 69.90 \\
\hline Primverin & 95,0 & 1.18 & $y=12488.0 x-3594.7$ & 0.9999 & $0.407-40.660$ & 7.95 & 26.52 \\
\hline Primulaverin & 95,2 & 0.96 & $y=2785.4 x-5313.2$ & 0.9999 & $0.395-39.520$ & 38.39 & 127.96 \\
\hline
\end{tabular}

performed on a Shimadzu chromatograph equipped with an SIL-20A autosampler, an SPD-M10A VP PDA photodiode array detector, and CLASS VP 7.3 chromatography software (Shimadzu, Kyoto, Japan). The content of the determined compounds was calculated in $\mathrm{mg}$ per $100 \mathrm{~g}$ of dry weight (DW).

The analysis of flower extracts was carried out using a binary gradient of deionized water adjusted to $\mathrm{pH} 3$ with phosphoric acid (Sigma-Aldrich, Poznań, Poland, reagent grade) (mobile phase A) and ACN (Sigma-Aldrich, Poznań, Poland, gradient grade) (mobile phase B) as follows: $0.01 \mathrm{~min}$, $12.5 \% \mathrm{~B} ; 4.0 \mathrm{~min}, 23 \% \mathrm{~B} ; 6.0 \mathrm{~min}, 60 \% \mathrm{~B} ; 6.1 \mathrm{~min}, 12.5 \% \mathrm{~B}$; $10 \mathrm{~min}$, stop. The flow rate was $1.5 \mathrm{ml} / \mathrm{min}$, oven temperature $40^{\circ} \mathrm{C}$ and injection volume $1 \mu \mathrm{l}$. Data were recorded at wavelength of $206 \mathrm{~nm}$ for (+)-catechin, $254 \mathrm{~nm}$ for luteolin 8-C-glucoside (orientin), quercetin 3-O-rutinoside (rutoside), quercetin 3-O-galactoside (hyperoside), isorhamnetin3-O-rutinoside, isorhamnetin-3-O-glucoside, $264 \mathrm{~nm}$ for kaempferol 3-O-glucoside (astragalin), and $330 \mathrm{~nm}$ for 3-Ocaffeoylquinic acid (chlorogenic acid).

For separation of root extract compounds, a binary gradient of deionized water adjusted to $\mathrm{pH} 3$ with phosphoric acid (Sigma-Aldrich, Poznań, Poland, reagent grade) (mobile phase A) and ACN (Sigma-Aldrich, Poznań, Poland, gradient grade) (mobile phase B) was used as follows: $0.01 \mathrm{~min}, 18 \% \mathrm{~B}$; $2.50 \mathrm{~min}, 20 \% \mathrm{~B}$; $2.51 \mathrm{~min}, 95 \% \mathrm{~B}$; $3.50 \mathrm{~min}, 95 \% \mathrm{~B}$; $3.54 \mathrm{~min}$, $18 \% \mathrm{~B}, 5 \mathrm{~min}$, stop. The flow rate was $1.3 \mathrm{ml} / \mathrm{min}$, oven temperature $32^{\circ} \mathrm{C}$, and injection volume $1 \mu \mathrm{l}$. Compounds were monitored at wavelength of $254 \mathrm{~nm}$ for primverin and $300 \mathrm{~nm}$ for primulaverin.

Peak identification was confirmed by comparison of retention time and UV spectra with adequate parameters of standards. Commercially available standards of the investigated compounds (ChromaDex ${ }^{\circledR}$, Irvine, USA) were separately dissolved with methanol (Sigma-Aldrich, Poznań, Poland) in a $10 \mathrm{ml}$ volumetric flask according to the ChromaDex's Tech Tip 0003: Reference Standard Recovery and Dilution and then used as standard stock solutions (https:// www.chromadex.com/media/2126/techtip0003-recoverydilutionprocedures_nl_pw.pdf). Working standard solutions were prepared by dilution of $10,50,100,200,500$, or $1000 \mu \mathrm{l}$ stock solutions of each compound with methanol in $10 \mathrm{ml}$ volumetric flasks. The working solutions were injected $(10.0 \mu \mathrm{l})$ on a column in six replicates $(n=6)$ using SIL-20A autosampler (Shimadzu, Kyoto, Japan) to generate a six-point calibration curve. Standard curve parameters were calculated using Microsoft Excel 14 (Table 1). The signal-to-noise (S/N) ratio approach was used to determine LOD (S/N of $3: 1)$ and LOQ (S/N of $10: 1)$.

2.3. Statistical Analysis. Data were subjected to statistical analysis using Statgraphics Plus for Windows v. 4.1 software. The mean values were compared using one-way analysis of variance (ANOVA) and expressed as means with standard deviation (SD) and coefficients of variation (CV\%). The differences between individual means were considered to be significant at $p<0.01$.

\section{Results and Discussion}

According to Wichtl [1], the total content of flavonoids in Primula flowers is up to about $3 \%$. To date in $P$. veris extracts, quercetin, quercetin-3-O-rutinoside, quercetin-3-O-gentiobioside, quercetin-trihexoside, kaempferol, kaempferol-3-Odiglucoside-7-O-glucoside, kaempferol-3-rutinoside, kaempferol-3-O-galactoside-rhamnoside-7-O-rhamnoside, luteolin, isorhamnetin, isorhamnetin-3-O-glucoside, isorhamnetin3-O-rutinoside, limocitrin-3-O-glucoside, limocitrin-3-Orutinoside, apigenin, catechin, epicatechin, and epigallocatechin, as well as some methoxylated flavones, have been identified using LC-MS and HPLC techniques [16-18, 23, 24]. Data on the composition of $P$. elatior flowers are much more scarce. These indicate the presence of rutoside, kaempferol3-rutinoside, and isorhamnetin-3-glucoside [1].

The above authors report only the chemical composition of flavonoids isolated from both Primula flowers. There is little information on the content of those substances. According to Wichtl [1], flowers of $P$. elatior are characterized by a higher content of rutoside $(0.54 \%)$ than the flowers of $P$. veris $(0.16 \%)$. Our results confirm the presence of six 
TABLE 2: The content of identified phenolic compounds in P. veris and P. elatior flowers (mg/100 g DW).

\begin{tabular}{|c|c|c|c|c|c|c|}
\hline \multirow{2}{*}{ Identified phenolic compounds } & \multicolumn{3}{|c|}{ P. veris } & \multicolumn{3}{|c|}{ P. elatior } \\
\hline & Mean & $\pm \mathrm{sd}$ & $\mathrm{CV}(\%)$ & Mean & $\pm s d$ & $\mathrm{CV}(\%)$ \\
\hline$(+)$-Catechin & 312.11 & $\pm 90.91^{* *}$ & 29.13 & 171.75 & \pm 57.26 & 33.34 \\
\hline Orientin & 204.23 & $\pm 78.03 \mathrm{~ns}$ & 38.21 & 149.13 & \pm 57.16 & 38.33 \\
\hline Rutoside & 630.83 & \pm 199.15 & 31.57 & 1025.96 & $\pm 237.21^{* *}$ & 23.12 \\
\hline Hyperoside & nd & & & 265.30 & \pm 122.80 & 46.29 \\
\hline Isorhamnetin-3-O-rutinoside & 740.24 & \pm 337.09 & 45.54 & 1142.75 & $\pm 401.76^{* *}$ & 35.16 \\
\hline Isorhamnetin-3-O-glucoside & 448.45 & $\pm 143.39^{* *}$ & 31.97 & 124.73 & \pm 54.02 & 43.31 \\
\hline Astragalin & 185.07 & $\pm 38.79^{* *}$ & 20.96 & 117.27 & \pm 34.81 & 29.68 \\
\hline Chlorogenic acid & 72.84 & $\pm 22.81 \mathrm{~ns}$ & 31.31 & 55.38 & \pm 21.04 & 37.99 \\
\hline
\end{tabular}

Values are the mean \pm standard deviation $(n=8){ }^{* *} p<0.01$, ns: insignificant difference, nd: not detected, and CV: coefficient of variation.

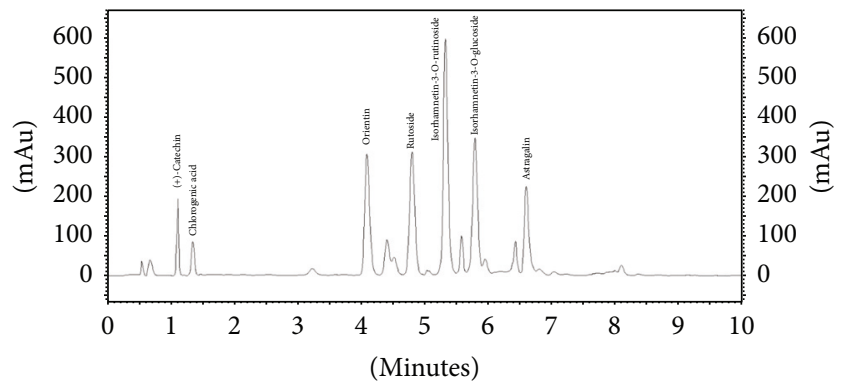

- Spectrum max plot

FIGURE 3: HPLC chromatogram of methanolic extract of the flowers of Primula veris.

flavonoid compounds in the flowers of both species, namely, orientin (luteolin-8-C-glucoside), rutoside (quercetin 3O-rutinoside), isorhamnetin-3-O-rutinoside, isorhamnetin3-O-glucoside, astragalin (kaempferol-3-O-glucoside), and (+)-catechin. The contents of isorhamnetin-3-O-glucoside, astragalin, and $(+)$-catechin were distinctly higher in the flowers of $P$. veris, that is, $448.45,185.07$, and $312.11 \mathrm{mg} / 100 \mathrm{~g}$ DW, respectively. In turn, rutoside and isorhamnetin-3-Orutinoside were detected in higher amounts in $P$. elatior (1025.96 and $1142.72 \mathrm{mg} / 100 \mathrm{~g}$ DW, resp.). A clear difference between both species concerned the presence of hyperoside (quercetin 3-O-galactoside), which was only identified in P. elatior flowers $(265.30 \mathrm{mg} / 100 \mathrm{~g}$ DW) (Table 2, Figures 3 and 4 ). Among the analyzed substances, the content of this compound was also the most diversified (CV 46.26\%).

According to Kim et al. [25], hyperoside indicates antiinflammatory and antioxidant activities. Results obtained by $\mathrm{Wu}$ et al. [26] show that this compound reveals antiviral activity, while Kohlmünzer [27] also mentions diuretic and hypotensive effects. In turn, rutoside is known for its strong antioxidant potential as well as antimicrobial and antiinflammatory activities [28]. Thus, this may explain the application of flowers of both Primula species in the treatment of coughs and respiratory tract diseases. The results of this study show that both hyperoside and rutoside differentiated the investigated species to a considerable degree. Therefore, flowers of $P$. elatior, which are rich in hyperoside and

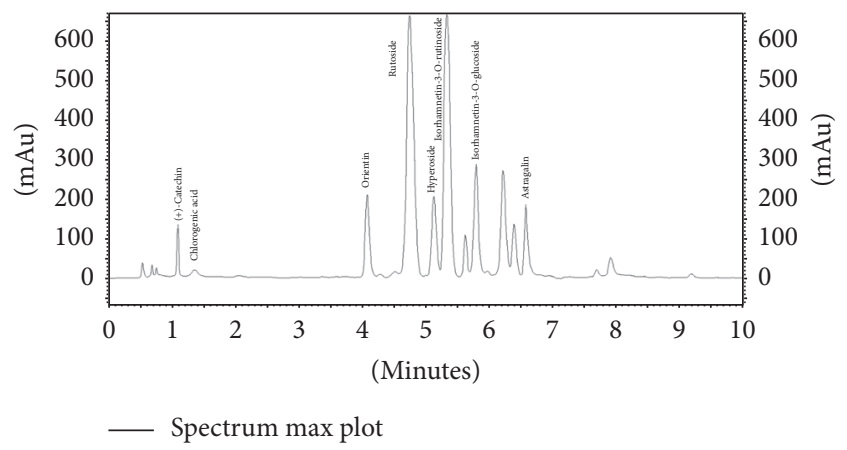

FIGURE 4: HPLC chromatogram of methanolic extract of the flowers of Primula elatior.

characterized by a higher content of rutoside in comparison to $P$. veris, may indicate stronger pharmacological activity. Unlike in the data presented by Wichtl [1], both species contained isorhamnetin-3-glucoside in their flowers (Table 2, Figures 3 and 4). Similar to hyperoside, the diversity of the content of both isorhamnetin derivatives was very high. However, the content of isorhamnetin-3-O-rutinoside was diversified to a higher degree for $P$. veris ( $\mathrm{CV} 45.54 \%$ ), while for isorhamnetin-3-O-glucoside this was seen in $P$. elatior (CV 43.31\%). According to Teng et al. [29], isorhamnetin aglycon reveals cytotoxic activity toward human hepatocellular carcinoma cells. In our study, the presence of one phenolic acid (chlorogenic acid) in both Primula flowers was also confirmed, and its content was similar in $P$. veris and $P$. elatior (72.84 and $55.38 \mathrm{mg} / 100 \mathrm{~g} \mathrm{DW}$, resp.).

Primverin and primulaverin (phenolic glycosides) are typical compounds of $P$. veris and $P$. elatior underground organs. The presence of these substances in Primula roots had been previously confirmed by Müller et al. [18]. According to EMA [8], their content in both species is very diversified and may be as high as $2.3 \%$. They are responsible for the specific odor of the raw material, which appears during the drying process [1]. In our study, the content of both compounds was ten times higher in $P$. veris (1183.32 and $536.16 \mathrm{mg} / 100 \mathrm{~g}$ DW, resp.) than in P. elatior (110.31 and $74.40 \mathrm{mg} / 100 \mathrm{~g} \mathrm{DW}$, resp.) roots (Table 3, Figures 5 and 6). Such a relationship had previously been reported only for primverin [18]. In addition, 
TABLE 3: The content of identified phenolic compounds in P. veris and P. elatior roots (mg/100 g DW).

\begin{tabular}{|c|c|c|c|c|c|c|}
\hline \multirow{2}{*}{ Identified phenolic compounds } & \multicolumn{3}{|c|}{ P. veris } & \multicolumn{3}{|c|}{ P. elatior } \\
\hline & Mean & $\pm \mathrm{sd}$ & CV (\%) & Mean & $\pm s d$ & $\mathrm{CV}(\%)$ \\
\hline Primverin & 1183.32 & $\pm 212.52^{* *}$ & 17.96 & 110.31 & \pm 26.03 & 23.60 \\
\hline Primulaverin & 536.16 & $\pm 168.32^{* *}$ & 31.39 & 74.40 & \pm 33.35 & 44.83 \\
\hline
\end{tabular}

Values are the mean \pm standard deviation $(n=8) ;{ }^{* *} p<0.01, \mathrm{CV}$ : coefficient of variation.

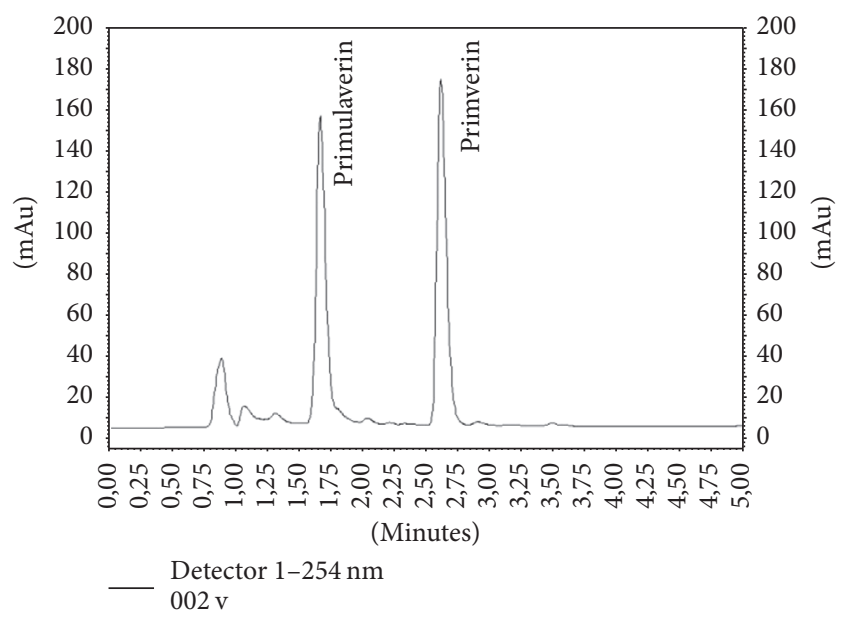

FIGURE 5: HPLC chromatogram of methanolic extract of the roots of Primula veris.

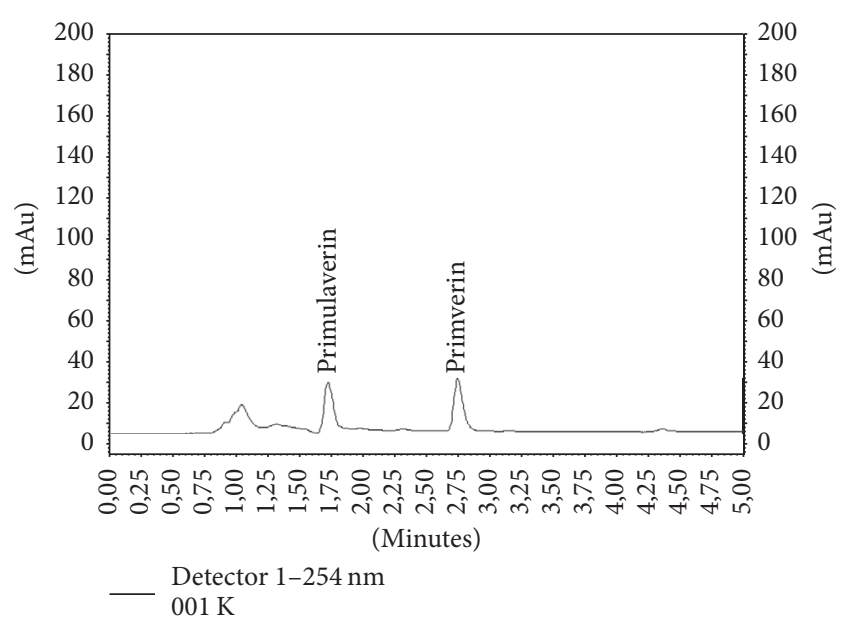

FIGURE 6: HPLC chromatogram of methanolic extract of the roots of Primula elatior.

the results of our study confirm that the content of primverin was much less diversified in both species than the content of primulaverin (Table 3 ).

According to our results, the use of a column with porous outer layer on solid silica core particles significantly reduces the analysis time and mobile phase consumption in comparison to existing methods [17, 18]. As a result, the analysis of phenolics in Primula raw materials can be effected faster and at lower cost and can be performed on standard (older) chromatographic systems.

The data concerning the chemical profile of other Primula species are fragmentary. Hashimoto et al. [30] identified three flavonol glycosides in $P$. sieboldii flowers and leaves, that is, quercetin and kaempferol derivatives, as well as two anthocyanins, that is, malvidin and petunidin glycosides, which were detected only in the flowers. In turn, Ozkan et al. [31] used HPLC to assess the content of catechin, rutin, and some phenolic acids, namely, gallic, protocatechuic, p$\mathrm{OH}$ benzoic, vanillic, and $\mathrm{p}$-coumaric acids in $P$. vulgaris flowers. According to this analysis, rutin and p-coumaric acid seemed to be the main phenolic compound of this raw material. In other Primula species, that is, $P$. denticulata, $P$. auricular, $P$. halleri, $P$. malacoides, and $P$. marginata, primetin (5,8-dihydroxyflavone), which is responsible for strong sensitizing properties, was also detected [32]. Depending on the chemical composition and content of biologically active compounds, different plant species of the genus have been used for various medicinal purposes, such as food poisoning, indigestion, dysentery, and ulcers as well as coughs or bronchitis, which are typical ailments treated with $P$. veris and P. elatior extracts.

\section{Conclusions}

Our results show distinct differences in terms of the content and composition of phenolic compounds identified in $P$. veris and P. elatior raw materials. Primula elatior flowers seem to be an interesting source of flavonoids. They are rich in rutoside and hyperoside, which reveal numerous pharmacological activities, that is, anti-inflammatory, antioxidant, and antimicrobial. Thus, they can be considered more interesting for the herbal medicine industry than $P$. veris. In turn, hyperoside was only found in the flowers of $P$. elatior, which may be used in the identification of Primula species. Flowers of neither species contained primverin or primulaverin. These substances were only identified in the roots. Primula veris was characterized by a ten times higher content of both phenolic glycosides in comparison with P. elatior.

Phenolic compounds identified in our study, especially hyperoside, primverin, and primulaverin, may be applied as chemical markers in the identification of Primula species as well as quality markers for their raw materials sourced from both natural sites and cultivated ones. The proposed analytical methods for the determination of these compounds in plant material are fast and reliable and can be performed on every standard HPLC system. 


\section{Conflicts of Interest}

The authors declare that there are no conflicts of interest regarding the publication of this paper.

\section{Acknowledgments}

The studies were supported by the Polish Ministry of Agriculture and Rural Development, within the Multiannual Programme "Creating the Scientific Basis of the Biological Progress and Conservation of Plant Genetic Resources as a Source of Innovation to Support Sustainable Agriculture and Food Security of the Country 2015-2020.”

\section{References}

[1] M. Wichtl, Ed., Herbal Drugs and Phytopharmaceuticals, A Handbook of Practice on a Scientific Basis, CRC Press, Stuttgart, Germany, 3rd edition, 2004.

[2] K. Kálmán, A. Medvegy, Z. Pénzes, and E. Mihalik, "Morphspecific variation of floral traits associated with reciprocal herkogamy in natural populations of Primula vulgaris and Primula veris," Plant Systematics and Evolution, vol. 268, no. 1-4, pp. 15-27, 2007.

[3] R. Brys and H. Jacquemyn, "Biological Flora of the British Isles: Primula veris L.," Journal of Ecology, vol. 97, no. 3, pp. 581-600, 2009.

[4] European Pharmacopoeia, "Primula root (Primulaeradix)," in European Directorate for the Quality of Medicines and Health Care (EDQM), pp. 2310-2311, Council of Europe, Strasbourg, France, 5th edition, 2006.

[5] British Herbal Pharmacopoeia, Primula veris, British Herbal Medicine Association, London, UK, 1974.

[6] Pharmacopeé Française, L'Adapharm, 10th edition, 1988.

[7] EMA (European Medicines Agency), "Assessment report on Primulaveris L. and/or Primulaelatior (L.) Hill, flos," EMA/HMPC/136583/2012, 2012.

[8] EMA (European Medicines Agency), "Assessment report on Primulaveris L. and/or Primulaelatior (L.) Hill, radix," EMA/ HMPC/113577/2012EMA, 2012.

[9] M. Zielińska-Pisklak and Ł. Szeleszczuk, "Pierwiosnek, nie tylko zwiastun wiosny!, drug in Poland," Farmakoterapia, vol. 23, no. 1, pp. 1-4, 2013.

[10] B. Gamze, A. Özmen, H. H. Biyik, and Ö. Şen, "Antimitotic and antibacterial effects of the Primula veris L. flower extracts," Caryologia, vol. 61, no. 1, pp. 88-91, 2008.

[11] J. H. Wiersema and B. Leon, World Economic Plants: A Standard Reference, CRC Press LLC, Boca Raton, Fla, USA, 1999.

[12] N. Demir, A. A. Gungor, H. Nadaroglu, and Y. Demir, "The antioxidant and radical scavenging activities of Primrose (Primula vulgaris)," European Journal of Experimental Biology, vol. 4, pp. 395-401, 2014.

[13] S. V. Tokalov, B. Kind, E. Wollenweber, and H. O. Gutzeit, "Biological Effects of Epicuticular Flavonoids from Primula denticulata on Human Leukemia Cells," Journal of Agricultural and Food Chemistry, vol. 52, no. 2, pp. 239-245, 2004.

[14] Q. Najmus-Saqib, F. Alam, and M. Ahmad, "Antimicrobial and cytotoxicity activities of the medicinal plant Primula macrophylla," Journal of Enzyme Inhibition and Medicinal Chemistry, vol. 24, no. 3, pp. 697-701, 2009.
[15] K. Aslam, I. A. Nawchoo, and B. A. Ganai, "In vitro antioxidant, antibacterial activity and phytochemical studies of Primula denticulata an important medicinal plant of Kashmir Himalaya," International Journal of Pharmacological Research, vol. 5, pp. 49-56, 2015.

[16] M. Stefova, S. Kulevanova, and T. Stafilov, "Assay of flavonols and quantification of quercetin in medicinal plants by HPLC with UV-diode array detection," Journal of Liquid Chromatography and Related Technologies, vol. 24, no. 15, pp. 2283-2292, 2001.

[17] L. Apel, D. Kammerer, F. Stintzing, and O. Spring, "Comparative metabolite profiling of triterpenoid saponins and flavonoids in flower color mutations of Primula veris L," International Journal of Molecular Sciences, vol. 18, no. 1, article 153, pp. 1-13, 2017.

[18] A. Müller, M. Ganzera, and H. Stuppner, "Analysis of phenolic glycosides and saponins in Primula elatior and Primula veris (primula root) by liquid chromatography, evaporative light scattering detection and mass spectrometry," Journal of Chromatography A, vol. 1112, no. 1-2, pp. 218-223, 2006.

[19] E. de Rijke, P. Out, W. M. A. Niessen, F. Ariese, C. Gooijer, and U. A. T. Brinkman, "Analytical separation and detection methods for flavonoids," Journal of Chromatography A, vol. 1112, no. 1-2, pp. 31-63, 2006.

[20] X. Q. Gao and L. Björk, "Valerenic acid derivatives and valepotriates among individuals, varieties and species of Valeriana," Fitoterapia, vol. 71, no. 1, pp. 19-24, 2000.

[21] D. Kumar, V. Arya, Z. A. Bhat, N. A. Khan, and D. N. Prasad, "The genus Crataegus: Chemical and pharmacological perspectives," Brazilian Journal of Pharmacognosy, vol. 22, no. 5, pp. 1187-1200, 2012.

[22] S. Gharibi, B. E. S. Tabatabaei, and G. Saeidi, "Comparison of Essential Oil Composition, Flavonoid Content and Antioxidant Activity in Eight Achillea Species," Journal of Essential OilBearing Plants, vol. 18, no. 6, pp. 1382-1394, 2015.

[23] Karl Chr., G. Mueller, and P. A. Pedersen, "Flavonoids in the flowers of Primula officinalis," Planta Medica, vol. 41, no. 1, pp. 96-99, 1981.

[24] C. W. Huck, C. G. Huber, K.-H. Ongania, and G. K. Bonn, "Isolation and characterization of methoxylated flavones in the flowers of Primula veris by liquid chromatography and mass spectrometry," Journal of Chromatography A, vol. 870, no. 1-2, pp. 453-462, 2000.

[25] S.-J. Kim, J.-Y. Um, S.-H. Hong, and J.-Y. Lee, "Antiinflammatory activity of hyperoside through the suppression of nuclear factor- $\kappa \mathrm{B}$ activation in mouse peritoneal macrophages," American Journal of Chinese Medicine, vol. 39, no. 1, pp. 171-181, 2011.

[26] L. Wu, X. Yang, Z. Huang, H. Liu, and G. Wu, "In vivo and in vitro antiviral activity of hyperoside extracted from Abelmoschus manihot (L) medik," Acta Pharmacologica Sinica, vol. 28, no. 3, pp. 404-409, 2007.

[27] S. Kohlmünzer, Farmakognozja, Wydawnictwo Lekarskie PZWL, Warsaw, Poland, 5th edition, 2013.

[28] L. S. Chua, "A review on plant-based rutin extraction methods and its pharmacological activities," Journal of Ethnopharmacology, vol. 150, no. 3, pp. 805-817, 2013.

[29] B.-S. Teng, Y.-H. Lu, Z.-T. Wang, X.-Y. Tao, and D.-Z. Wei, "In vitro anti-tumor activity of isorhamnetin isolated from Hippophae rhamnoides L. against BEL-7402 cells," Pharmacological Research, vol. 54, no. 3, pp. 186-194, 2006.

[30] N. Hashimoto, R. Ohsawa, J. Kitajima, and T. Iwashina, "New flavonol glycosides from the leaves and flowers of Primula 
sieboidii," Natural Product Communications, vol. 10, no. 3, pp. 421-423, 2015.

[31] T. M. Ozkan, R. Aliyazicioglu, S. Demir et al., "Phenolic characterization and antioxidant activity of Primula vulgaris and its antigenotoxic effect on fibroblast cell," Jundishapur Journal of Natural Pharmaceutical Products, article e40073, 2016.

[32] K. Aslam, I. A. Nawchoo, M. A. Bhat, A. H. Ganie, and N. Aslam, "Ethno-pharmacological review of genus Primula," International Journal of Advanced Research, vol. 2, no. 4, pp. 2934, 2014. 

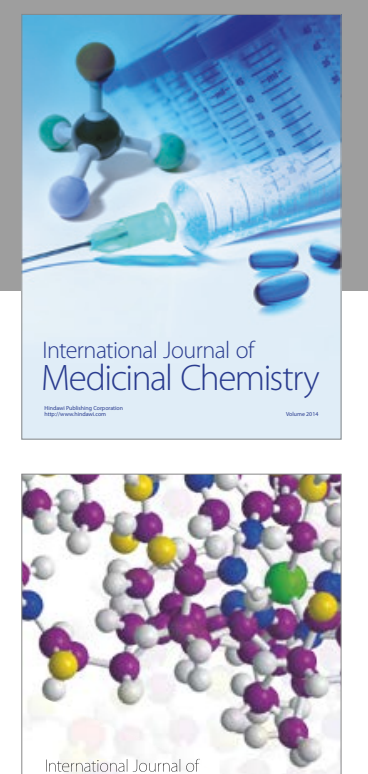

Carbohydrate Chemistry

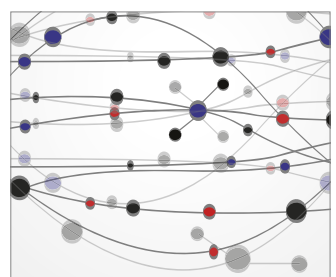

The Scientific World Journal
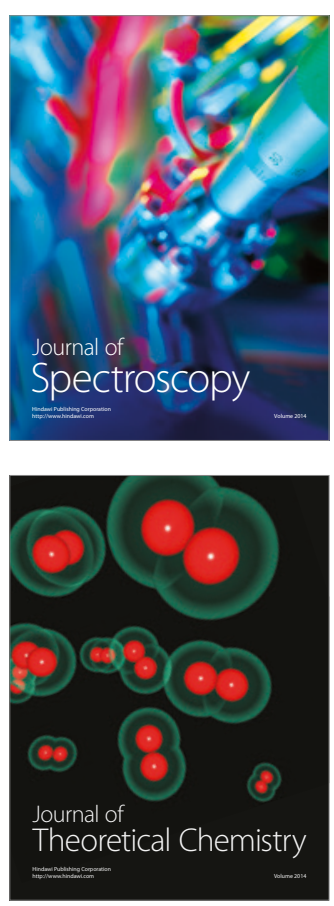
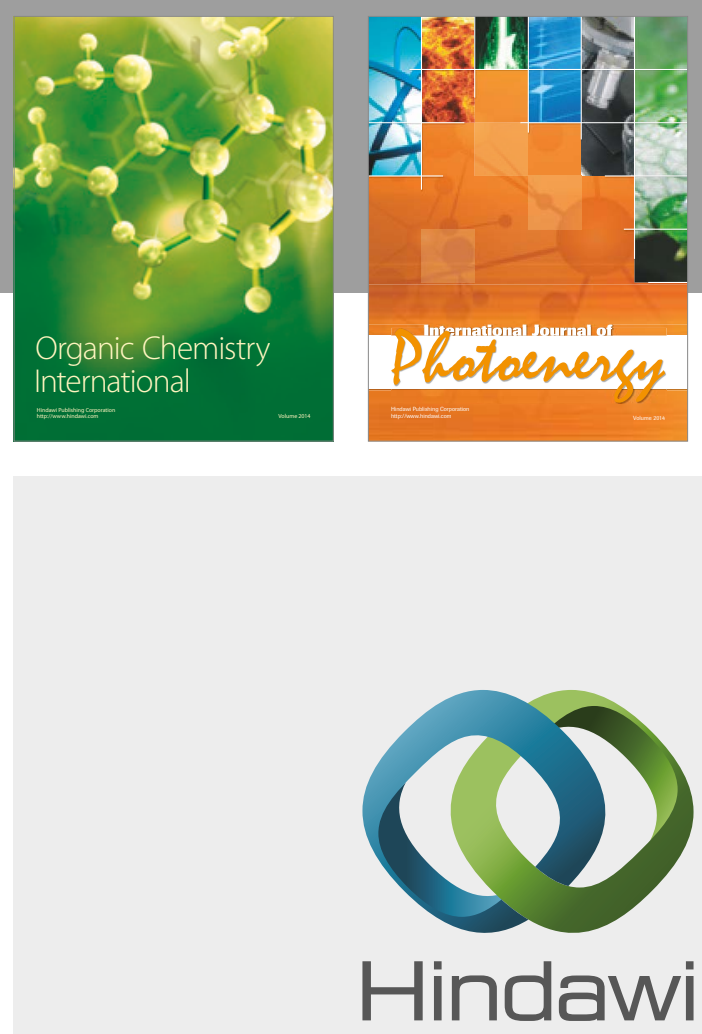

Submit your manuscripts at

https://www.hindawi.com

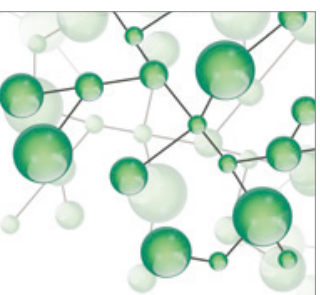

International Journal of

Inorganic Chemistry

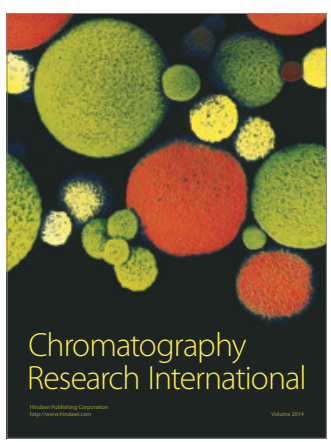

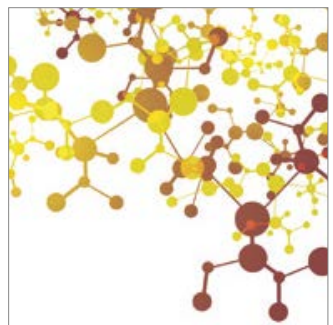

Applied Chemistry
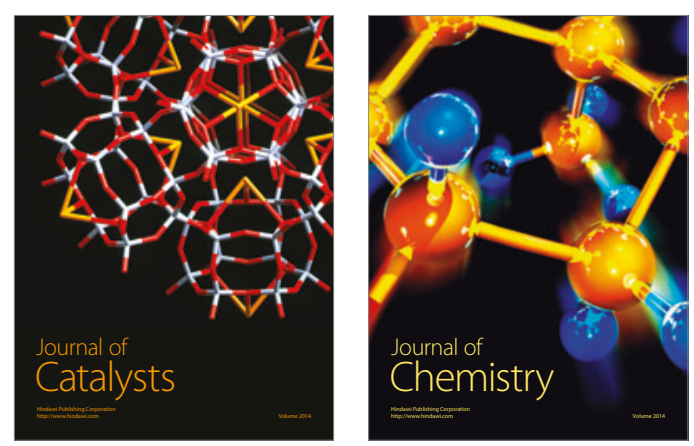
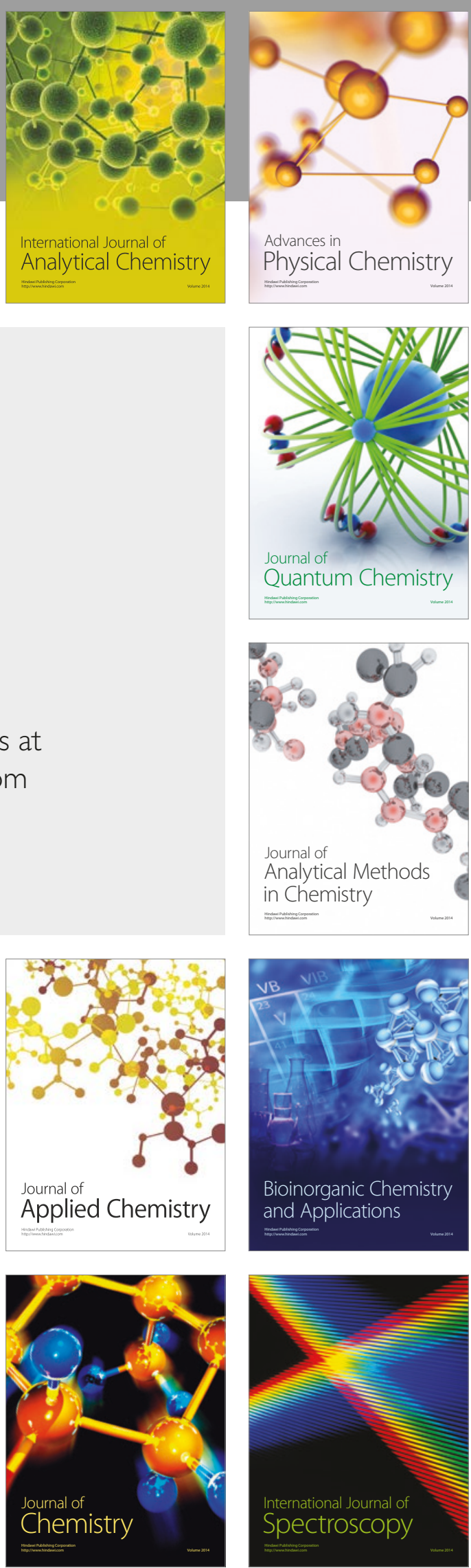